\title{
DNA fingerprinting of the Asian stinging catfish (Heteropneustes fossilis, Bloch) by Random Amplified Polymorphic DNA markers
}

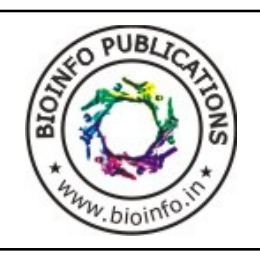

Sultana S., Akter S., Hossain M.A.R. and Alam M.S. *

Department of Fisheries Biology and Genetics, Bangladesh Agricultural University, Mymensingh 2202, Bangladesh, samsul_bau@yahoo.com

\begin{abstract}
The availability of the stinging catfish, Heteropneustes fossilis has been declined in the natural water bodies in Bangladesh in the last two decades. Thus, it is a great concern whether the reduction in abundance has had any impact on genetic variability of this species. Randomly Amplified Polymorphic DNA (RAPD) fingerprint was generated to analyze the genetic variation in five different populations of $H$. fossilis namely Chalan beel (Natore), Pirgonj beel (Rangpur), Mohongonj haor (Netrakona), Belaboo beel (Narsingdi) and a hatchery located in Mymensingh. Four polymorphic decamer primers, out of 30 tested, were selected for Polymerase Chain Reaction and used in the final RAPD analysis of fifteen individuals from each population. These four primers produced 31 scorable bands of which 26 (83.87\%) were polymorphic. The proportion of polymorphic loci and gene diversity estimates were 83.87 and 0.3703 , respectively in the Mohongonj population indicating the existence of a relatively higher level of genetic variation in this population. All the populations showed almost similar level of intra-population similarity indices. The UPGMA dendrogram based on Nei's original measures of genetic distance (D) indicated the segregation of five populations into two distinct groups. The four natural populations made one cluster and the hatchery population produced another cluster. RAPD markers could detect variations within and between populations allowing genetic characterization of different populations of $H$. fossilis.
\end{abstract}

Key words: Stinging catfish, RAPD, genetic variability, DNA fingerprinting

\section{Introduction}

The stinging catfish, Heteropneustes fossilis, belongs to the family Heteropneustidae of the order Siluriformes. It is found in Bangladesh, India, Pakistan, Nepal, Srilanka, Thailand, Laos and Mayanmar [1]. It is commercially as well as aquaculturally an important species in many Asian countries. It occurs in all types of inland water bodies and can survive for a long time even in a small quantity of water as it has accessory respiratory (air-breathing) organs. The species is popular for its high growth rate, high fecundity, efficient feed utilization capacity and ability to survive in poorly oxygenated waters. It is also popular from nutritional and medical point of view. Habitat degradation caused by natural and human interventions, injudicious application of pesticides in agricultural fields and release of industrial effluents have recently become great constraints for fish biodiversity in most aquatic ecosystems in Bangladesh. As a result there is a declining trend in the availability of $H$. fossilis along with many others in natural water bodies of the country. An outbreak of epizootic ulcerative syndrome (EUS) during the late eighties and early nineties of the last century aggravated the loss of abundance of this species in Bangladesh. It has been categorized as vulnerable based on IUCN red list of 1994 in India [2]. Thus, it is a great concern whether the reduction in population size has had any impact on genetic variability of this species as there is an inverse relationship between the genetic variability and adaptability to environmental changes. Genetic variability is also termed as raw materials for selective improvement of an aquaculture species.
Recently, this species has been used as an aquaculture species by private fish farmers and for that purpose the seeds are being produced in some hatcheries. The popularity of farming of this species is increasing day by day due to its high market price and demand.

Molecular markers are realistic and useful tools for the investigation and monitoring of genetic conditions both in natural populations and in captive stocks. RAPD is one of the simplest molecular tools for genetic and systematic analyses of various organisms and has provided important applications in catfish [3]. The RAPD technique is relatively less expensive compared to other methods [4] and does not require prior DNA sequence information for examination of genomic variations. The objective of the present study is to generate RAPD fingerprinting of $H$. fossilis to assess intra and inter-population genetic variation in five stocks of this species.

\section{Materials and Methods \\ Collection of fish sample and extraction of genomic DNA}

$H$. fossilis samples were collected from four natural and one hatchery sources namely Chalan beel (Natore), Pirgang beel (Rangpur), Mohongonj haor (Netrakona), Belaboo beel (Narsingdi) and Al-Amin Hatchery (Mymensingh) "Fig. (1)". A small piece of the caudal fin was cut with scissors and preserved in 95\% ethanol until used for genomic DNA extraction. Fifteen fish samples from each stock were analyzed by RAPD markers. 
Genomic DNA was extracted from fin tissues according to the method described by Islam and Alam [5]. In brief, approximately $30 \mathrm{mg}$ of fin tissues was cut into small pieces and taken into $1.5 \mathrm{ml}$ microfuge tube. The fin tissue was digested with proteinase- $K$ in extraction buffer (100 mM Tris, $10 \mathrm{mM}$ EDTA and $250 \mathrm{mM} \mathrm{NaCl}$, $\mathrm{pH}=8.0$ and $1 \%$ Sodium Dodecyl Sulfate) overnight at $37^{\circ} \mathrm{C}$. DNA was purified once with equal volume of phenol: chloroform: isoamyl alcohol (25:24:1) and once with chloroform: isoamyl alcohol (24:1) and precipitated using 0.6 volumes of isopropanol. The DNA samples were tested qualitatively on $1 \%$ agarose gel and quantified by using a spectrophotometer (Biophotometer plus, Eppendorf, Germany). DNA was isolated from fifteen fish of each of the sources and used for RAPD fingerprinting.

\section{Primer Selection and PCR amplification}

Initially, thirty decamer primers from three kits (5 from kit $A, 20$ from kit $B$ and 5 from kit $C$ ) of random sequence (Operon Technologies, Inc., Alameda, CA, USA) were tested on a randomly chosen fish from each populations. Primers were selected on the basis of intensity or resolution and repeatability of bands, and polymorphism. Finally, four primers exhibiting a high quality banding patterns and sufficient variability were used for analysis of all the samples. The PCR conditions were based on [6] with some modifications. PCR was performed on each DNA sample in a $10 \mu \mathrm{l}$ reaction mix containing $1 \mu \mathrm{l}$ of $10 \times$ Taq polymerase buffer, $2 \mu \mathrm{M}$ primer, $0.25 \mathrm{mM}$ of dNTPs 1.0 unit of Taq DNA polymerase (GENEI, Bangalore, India), and 100ng of genomic DNA. The reaction mix was preheated at $94^{\circ} \mathrm{C}$ for 3 min followed by 40 cycles of $1 \mathrm{~min}$ denaturation at $94^{\circ} \mathrm{C}, 1 \mathrm{~min}$ annealing at $36^{\circ} \mathrm{C}$ and 2 min elongation or extension at $72^{\circ} \mathrm{C}$. After the last cycle, a final step of 6 min at $72^{\circ} \mathrm{C}$ was added to allow complete extension of all the amplified fragments.

Agarose gel electrophoresis of PCR products Total volume of the amplified product $(10 \mu \mathrm{l})$ of each sample was subjected to electrophoresis on $1.4 \%$ agarose gel containing ethidium bromide in $1 \times$ TBE buffer at $100 \mathrm{~V}$ for $1 \mathrm{~h}$. Two molecular weight markers (Lambda DNA/EcoRI/HindIII digest and 100bp DNA ladder) were electrophoresed alongside the PCR products. Finally, the DNA bands were observed on a GelDoc system and the photographs were captured by a Digital Camera and saved.

\section{RAPD Data Analysis}

The RAPD data were scored for the presence or absence of the amplified fragments for all individuals of all the populations. The presence of a band was designated as 1 and absence was designated as 0 . For more accuracy, band scoring was performed by two persons independently. The basic data finally consisted of a binomial $(1,0)$ matrix. This was used for estimating polymorphic loci, Nei's [7] gene diversity, genetic distance and constructing an unweighted pair group method of arithmetic average (UPGMA) dendrogram among populations using the POPGENE (version 1.31) computer program [8]. The sizes of the RAPD markers were estimated by using the software DNAfrag (Version 3.03) [9]. Since RAPD markers are dominant, it was assumed that each band represented the phenotype at a single bi-allelic locus [6]. The similarity index values (SI) between the RAPD profiles of any two individuals on the same gel were calculated from RAPD markers according to the following formula:

Similarity index $(\mathrm{SI})=2 \mathrm{~N}_{\mathrm{AB}} /\left(\mathrm{N}_{\mathrm{A}}+\mathrm{N}_{\mathrm{B}}\right)$

Where, $N_{A B}$ is the total number of RAPD bands shared by individuals $A$ and $B$, and $N_{A}$ and $N_{B}$ are the number of fragments scored for each individual, respectively [10]. Within population similarity (Si) was calculated as the average of $\mathrm{SI}$ across all possible comparisons between individuals within a population. Between population similarity (Sij) was calculated as the average similarity between randomly paired individuals from populations $\mathrm{i}$ and $\mathrm{j}$ [11].

\section{Results}

The four primers generated a total of 31 bands of which 26 bands (83.87\%) were polymorphic (Table 1). The number of bands per primers ranged from 7-9 with an average of 7.75. The proportion of polymorphic bands for each primer ranged from $77.78 \%$ to $87.50 \%$. The proportion of polymorphic loci was highest in the Mohongonj Haor (Netrakona) population (83.87\%) and lowest in the Hatchery (Mymensingh) population $(64.52 \%)$ (Table 1$)$. The gene diversity across all populations for all RAPD loci ranged from $0.3139 \pm 0.19$ (mean \pm SD) to $0.3703 \pm 0.11$. RAPD profiles of five different populations of $H$. fossilis for the four primers OPA01, OPB01, OPB02 and OPB19 are shown in "Fig. (2)".

\section{Within and between population similarity indices}

The value for intra-population similarity indices for the Hatchery population was the highest $(71.77 \%)$ followed by that of the Natore $(71.06 \%)$, Narsingdi (67.42\%), Mohongonj (66.22\%) and Rangpur (64.95\%) populations respectively (Table 2). The inter-population SI (Sij) for the Natore vs Narsingdi populations was higher $(67.67 \%)$ than those for all other population-pairs (Table 2).

\section{Genetic identity and genetic distance}

The value for interpopulation genetic identity was highest (0.9397) for the Natore and Rangpur populations and lowest $(0.8444)$ for the 
Mohongonj and Hatchery populations. The highest (0.1691) and lowest (0.0622) genetic distances were found between the Hatchery and Mohongonj populations and between the Rangpur and Natore populations respectively (Table 3). The UPGMA dendrogram based on Nei's genetic distance [12] indicated the segregation of the $H$. fossilis populations collected from five different sites into two distinct clusters. The four natural populations remained in one cluster and the Hatchery population remained in the other cluster. The Natore and Rangpur populations produced one subcluster and the Mohongonj and Narsingdi belonged to another subcluster "Fig. (3)".

\section{Discussion}

The abundance of stinging catfish has decreased significantly owing mainly to imprudent development and reckless fishing during the last two decades and the occurrence of ulcerative disease syndrome in the late 1980s and early 1990s. Reduction in population size may result in the loss of gene genetic diversity and depletion in gene pool [13]. The RAPD markers have been found to have a wide range of applications in gene mapping, population genetics, molecular evolutionary genetics and plant and animal breeding [14, 15]. RAPD technique has been used in fisheries for analysis of variation in populations with differential degrees of geographic isolation. The four primers generated a total of 31 bands in the five populations $83.87 \%$ of which were polymorphic. The percentage of polymorphic loci in the five different populations of $H$. fossilis, was found to be similar to that observed in six populations of the African catfish Clarias gariepinus in Egypt 69.5\% [16]. In contrast to the findings of the present study, a very low level of polymorphism $(18.75 \%)$ in RAPD loci was observed in two Indian populations of $H$. fossilis (Bloch) [17]. However, the same authors [18] found a high level $(64.98 \%)$ of polymorphism in two populations of Mystus vittatus of Madhya Pradesh in India using RAPD markers. Liu and co-workers [19] observed very low levels of polymorphism within the species of both channel catfish (Ictalurus punctatus) and blue catfish (Ictalurus furcatus) but found high levels of polymorphism between the species of channel catfish (I. punctatus) and blue catfish ( $I$. furcatus). In the present study, a maximum of $83.87 \%$ polymorphic loci was found in the Mohongonj population and a relatively lower level of polymorphic loci $(64.52 \%)$ was found in the Hatchery population. A high level of polymorphic loci indicates the high genetic variation in the studied populations. The higher percentage of polymorphic loci and gene diversity (0.3703 \pm 0.1137$)$ in Mohongonj populations indicate the highest level of genetic variation in this population. All the populations showed almost similar levels of intra-population similarity indices which indicates that individuals within each population are genetically closer to each other than the individuals of the other populations (Table 2). Nei's [12] original measures of genetic distance (D) were also used to evaluate the genetic variability and relatedness among the $H$. fossilis populations. The pair-wise genetic distance between the Mohongonj and Hatchery populations was highest while that between the Rangpur and Chalan beel (Natore) populations was the lowest. On the geographical point of view, though the Hatchery located near to Mohongonj, and Chalan beel located quite far from the Rangpur but it shows close similarity with the Chalan beel populations. The UPGMA dendrogram based on the genetic distance produced two clusters of five populations. The four natural populations made one cluster and the Hatchery population made another cluster. The present study may serve as a reference point for future examinations of genetic variations within the populations of fishes which are not only commercially important but also play a significant role in food chain in lentic as well as lotic habitats. The presence of variability among populations as well as individuals within a population is essential for their ability to survive and successfully respond to environmental changes [20]. We found a quite high level of genetic variation in the five populations of $H$. fossilis. The genetic variations in the five studied populations were more or less similar.

Acknowledgement- This research was supported by Bangladesh Agricultural University Research System through a research project entitled "Study of population genetic structure of the stinging catfish Heteropneustes fossilis (Bloch)", No. 2009/26/AU.

\section{References}

[1] Talwar P.K. and Jhingran A.G. (1991) Inland Fishes of India and adjacent countries. Vol. 2. Published by Oxford \& IBH Publishing Co.Pvt Itd. New Delh, Bombay, Calcatta. 1158p.

[2] Dahanukar N., Raut R. and Bhat A. (2004) Journal Biogeography, 31 (2004), 123-136.

[3] Bartish I.V.,Gorkava L.P., Rumpunen K. and Nybom H. (2000) Theoretical AppliedGenetics, 101, 554-563.

[4] Ward R.D. and Grewe P.M. (1994) Reviews Fish Biology Fisheries, 4, 300325.

[5] Islam M.S. and Alam M.S. (2004) Journal Applied Ichthyology, 20, 407412.

[6] Williams J.G.K., Kubelik A.R., Livak K.J., Rafalski J.A. and Tingey S.V.

Copyright $($ C 2010, Bioinfo Publications, 
(1990) Nucleic Acids Research 18, 6531-6535.

[7] Nei M. (1973) Proceedings National Academy Sciences, USA 70, 33213323.

[8] Yeh F.C., Yang R.C. and Boyle T. (1999)popgene version 1.31: Microsoft Window based Freeware for Population Genetic Analysis. $\mathrm{ftp}: / / \mathrm{ftp} . \mathrm{microsoft.com} /$ Softlib/HPGL.EXE

[9] Nash J.H.E. (1991) DNAfrag, Version 3.03. Institute for Biological Sciences, National Research Council of Canada, Ottawa, Ontario, Canada.

[10] Lynch M. (1990) Molecular Biology Evolution, 7, 478-484.

[11] Lynch M. (1991) DNA fingerprinting: approaches and applications. Published by Birkhauser Verlag Basel, Switzerland, pp. 113-126.

[12] Nei M. (1972) American Naturalist, 106, 283-292.

[13] Nelson K. and Soule M. (1987) GeneticalConservation of Exploited Fishes. Published by University Washington Press, Seattle, pp. 345-368.

[14] Bardakci F. and Skibinski, D.O. (1994) Heredity, 73, 117-123.

[15] Ertas H. and Seker E. (2005) Turkish JournalVeterinary Animal Science, 29, 1007-1011.
[16] Saad Y.M., Hanafi M.S., Essa M.A., GuergesA.A. and Ali S.F. (2009) Global Veterinaria 3(6): 503-508.

[17] Garg R.K., Silawat N., Sairkar P., Vijay N. and Mehrotra N.N. (2009a) African JournalBiotechnology, 8, 4032-4038.

[18] Garg R.K., Sairkar P., Silawat N., Vijay N., Batav N. and Mehrotra, N.N. (2009b) International Journal Zoological Research, 5, 171-177.

[19] Liu Z. J.,Li P., Argue B.J. and Dunham R.A.(1999) Aquaculture, 174, 59-68.

[20] Ryman N., Utter F. and Laikre L. (1995) Reviews Fish Biology Fisheries, 5, 417446.

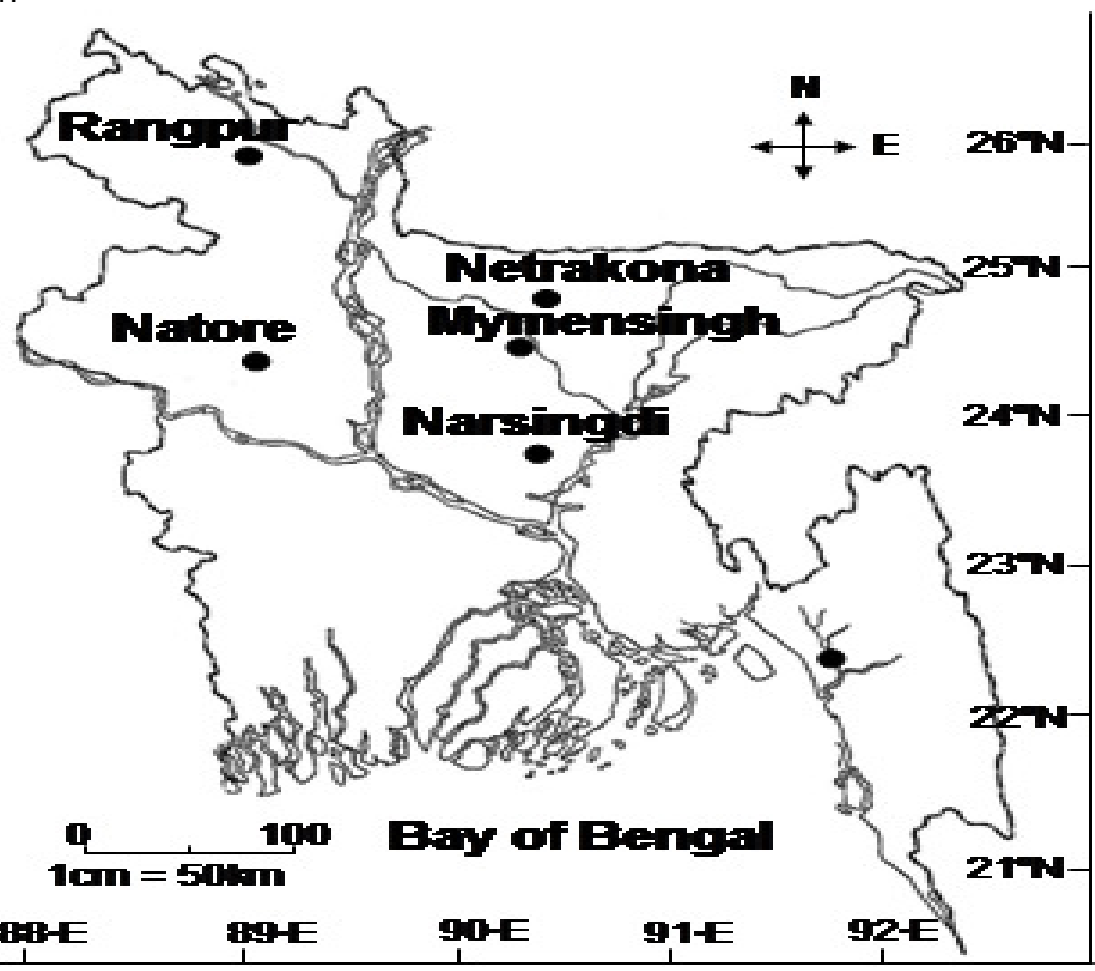

Fig. 1-Map of Bangladesh showing different sites (districts) where the $H$. fossilis samples were collected from for the study. 
4 1234567891011121314 t5
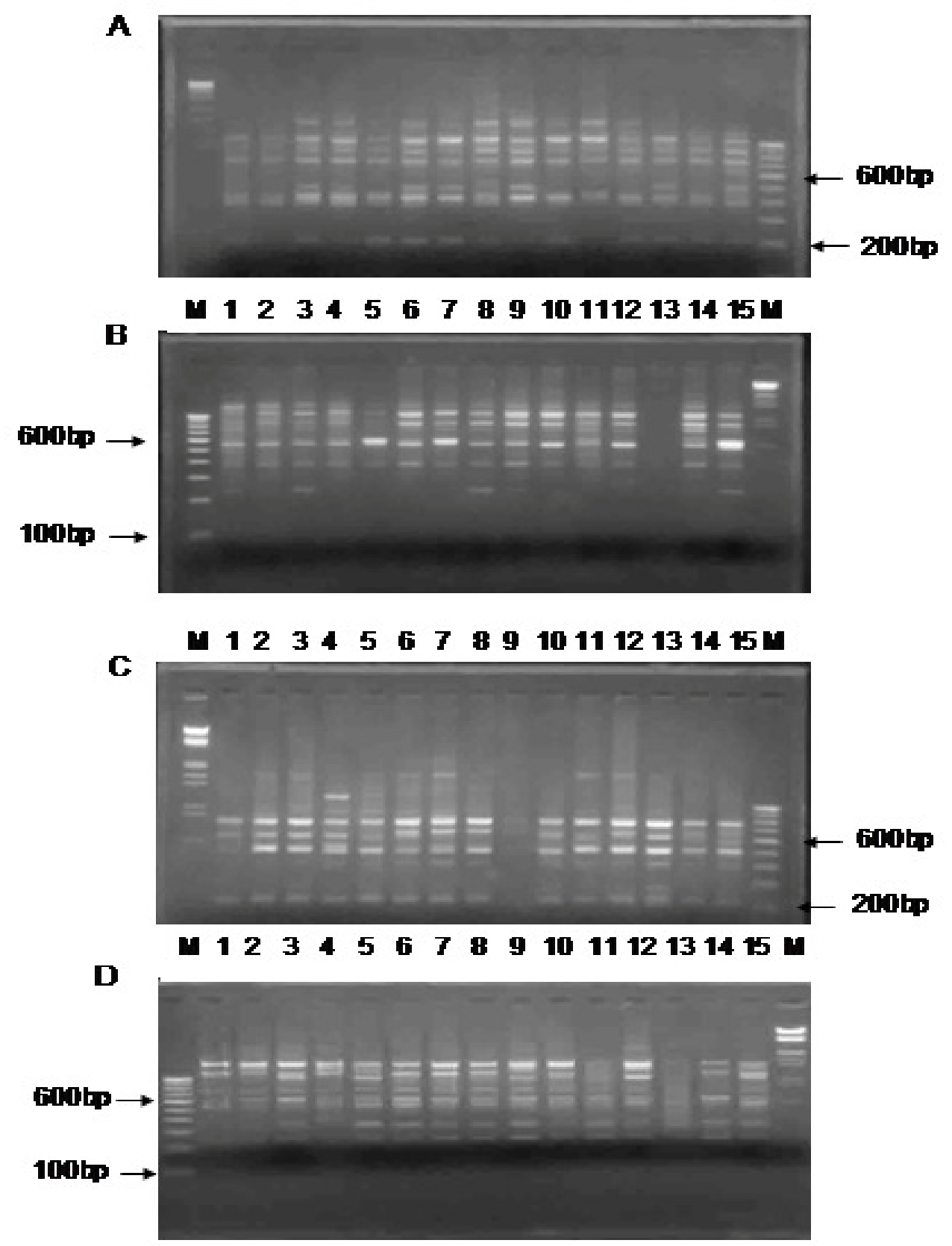

Ful 2

Fig. 2-RAPD profiles of $H$. fossilis for the primer OPA01 (A), OPB01 (B), OPB02 (C) and OPB19 (D). M: Molecular weight markers (Lambda DNA EcoRI/HindIII digest and 100bp DNA ladder. 


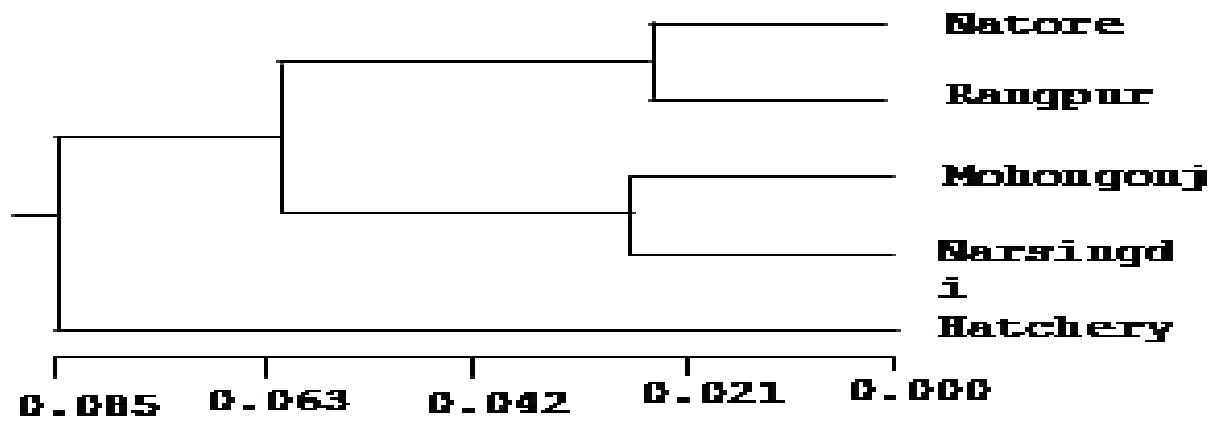

Gemetic distamce

Fig. 3- UPGMA dendrogram based on Nei's genetic distance showing genetic relationship among five populations of $H$. fossilis

Table 1- RAPD bands with corresponding primers scored and polymorphic bands for the five $H$. fossilis populations.

\begin{tabular}{|l|l|l|l|l|l|}
\hline Primers & Sequence $\left(5^{\prime}-3^{\prime}\right)$ & $\begin{array}{l}\text { No. of } \\
\text { scorable } \\
\text { bands }\end{array}$ & $\begin{array}{l}\text { Size range } \\
(\mathrm{bp})\end{array}$ & $\begin{array}{l}\text { Polymorphic } \\
\text { bands }\end{array}$ & $\begin{array}{l}\text { Polymorphism } \\
(\%)\end{array}$ \\
\hline OPA01 & CAGGCCCTTC & 7 & $309-509$ & 6 & 85.71 \\
\hline OPB01 & GTTTCGCTCC & 7 & $146-1234$ & 6 & 85.71 \\
\hline OPB02 & TGATCCCTGG & 9 & $172-5735$ & 7 & 77.78 \\
\hline OPB19 & ACCCCCGAAG & 8 & $131-1781$ & 7 & 87.50 \\
\hline
\end{tabular}

Table 2- Number and proportion of polymorphic loci, gene diversity and intra- and inter-population similarity indices in five different populations of $H$. fossilis.

\begin{tabular}{|c|c|c|c|c|}
\hline Population & $\begin{array}{l}\text { No. of } \\
\text { Polymorphic loci }\end{array}$ & $\begin{array}{l}\text { Percentage of } \\
\text { Polymorphic loci }\end{array}$ & Gene Diversity & $\begin{array}{l}\text { Similarity } \\
\text { Index }\end{array}$ \\
\hline Natore & 22 & 70.96 & $0.3546 \pm 0.169$ & 71.06 \\
\hline Rangpur & 23 & 74.19 & $0.3693 \pm 0.165$ & 64.95 \\
\hline Mohongonj & 26 & 83.87 & $0.3703 \pm 0.114$ & 66.66 \\
\hline Narsingdi & 24 & 77.42 & $0.3483 \pm 0.155$ & 67.42 \\
\hline Hatchery & 20 & 64.52 & $0.3139 \pm 0.187$ & 71.77 \\
\hline \multicolumn{5}{|c|}{ Inter-population similarity indices } \\
\hline \multicolumn{2}{|c|}{ Chalan beel-Narsingdi } & & & $67.67 \%$ \\
\hline \multicolumn{2}{|c|}{ Chalan beet-Rangpur } & & & $67.65 \%$ \\
\hline \multicolumn{2}{|c|}{ Narsingdi-Hatchery } & & & $67.16 \%$; \\
\hline \multicolumn{2}{|c|}{ Rangpur-Hatchery } & & & $66.16 \%$ \\
\hline \multicolumn{2}{|c|}{ Rangpur-Narsingdi } & & & $64.77 \%$ \\
\hline \multicolumn{2}{|c|}{ Mohongonj-Narsingdi } & & & $64.27 \%$ \\
\hline \multicolumn{2}{|c|}{ Chalan beel-Hatchery } & & & $62.94 \%$ \\
\hline \multicolumn{2}{|c|}{ Rangpur-Mohongonj } & & & $59.99 \%$ \\
\hline \multicolumn{2}{|c|}{ Mohongonj -Hatchery } & & & $56.27 \%$ \\
\hline \multicolumn{2}{|c|}{ Chalan beet- Mohongonj } & & & $56.26 \%$ \\
\hline
\end{tabular}

Table 3- Genetic identity (above diagonal) and genetic distance (below diagonal) between different populations pairs of H. fossilis ( Nei's original measure of genetic identity and genetic distance)

\begin{tabular}{|l|l|l|l|l|l|}
\hline Population & Natore & Rangpur & Mohongonj & Narsingdi & Hatchery \\
\hline Natore & $* \star \star$ & 0.9397 & 0.8895 & 0.8742 & 0.8633 \\
\hline Rangpur & 0.0622 & $* \star *$ & 0.9067 & 0.9212 & 0.8944 \\
\hline Mohongonj & 0.1171 & 0.0979 & $* * *$ & 0.9371 & 0.8444 \\
\hline Narsingdi & 0.1344 & 0.0821 & 0.0649 & $* *$ & 0.9107 \\
\hline Hatchery & 0.1470 & 0.1116 & 0.1691 & 0.0935 & $* * *$ \\
\hline
\end{tabular}

